\title{
A monoclonal thyroid-stimulating antibody
}

\author{
Takao Ando, ${ }^{1}$ Rauf Latif, ${ }^{1}$ Alla Pritsker, ${ }^{2}$ Thomas Moran, ${ }^{2,3}$ Yuji Nagayama, ${ }^{4}$ \\ and Terry F. Davies ${ }^{1}$
}

${ }^{1}$ Division of Endocrinology, Diabetes, and Bone Diseases, Department of Medicine, ${ }^{2}$ Hybridoma Shared Research Facility, and

${ }^{3}$ Department of Microbiology, Mount Sinai School of Medicine, New York, New York, USA

${ }^{4}$ Department of Pharmacology 1, Nagasaki University School of Medicine, Nagasaki, Japan

The thyrotropin receptor, also known as the thyroid-stimulating hormone receptor (TSHR), is the primary antigen of Graves disease. Stimulating TSHR antibodies are the cause of thyroid overstimulation and were originally called long-acting thyroid stimulators due to their prolonged action. Here we report the successful cloning and characterization of a monoclonal antibody (MS-1) with TSHR-stimulating activity. The thyroid-stimulating activity of MS-1 was evident at IgG concentrations as low as $20 \mathrm{ng} / \mathrm{ml}$. MS- 1 also competed for radiolabeled TSH binding to the native TSHR and was able to compete for TSH-induced stimulation. MS-1 recognized a conformational epitope within the TSHR $\alpha$ (or A) subunit but excluding the receptor cleavage region. Using an assay measuring loss of antibody recognition after cleavage we demonstrated that MS-1, in contrast to TSH, was unable to enhance TSHR posttranslational cleavage. Since receptor cleavage is followed by $\alpha$ subunit shedding and receptor degradation, the functional half-life of the receptor may be extended. The isolation and characterization of MS-1 provides a novel explanation for the prolonged thyroid stimulation in this disease which may be secondary to the lack of receptor cleavage in addition to the prolonged half-life of IgG itself.

$$
\text { J. Clin. Invest. 110:1667-1674 (2002). doi:10.1172/JCI200216991. }
$$

\begin{abstract}
Introduction
The thyrotropin receptor, also known as the thyroid-stimulating hormone receptor (TSHR), the primary antigen of Graves disease, has been studied extensively due to its unique posttranslational processing and role in human disease (1). Graves disease is a
\end{abstract}

Received for publication September 25, 2002, and accepted in revised form October 22, 2002.

Address correspondence to: Takao Ando, Mount Sinai School of Medicine, Box 1055, One Gustave L. Levy Place, New York, New York 10029, USA.

Phone: (212) 241-4129; Fax: (212) 241-4218; E-mail: takao.ando@mssm.edu.

Conflict of interest: The authors have declared that no conflict of interest exists.

Nonstandard abbreviations used: thyroidstimulating hormone receptor (TSHR); TSHR autoantibody (TSHR-Ab); Chinese hamster ovary (CHO); human TSHR (hTSHR); adenovirus vector incorporating full-length hTSHR (AdTSHR); cyclic AMP (cAMP); green fluorescent protein (GFP). common autoimmune disease associated with TSHR autoantibodies (TSHR-Ab's) with thyroid-stimulating activity. These stimulating TSHR-Ab's are characterized by binding to and activating TSHR, resulting in overstimulation of the thyroid gland and hyperthyroidism. Such thyroid glands show hypertrophy of the thyroid epithelial cells and a reduction in intrathyroidal stores of thyroglobulin as well as a focal lymphocytic infiltrate.

TSHR is a $G$ protein-coupled receptor expressed on the plasma membrane of the thyrocytes and also on a variety of other cell types (1). However, TSHR undergoes complex posttranslational processing quite different from the other glycoprotein hormone receptors. The pathophysiological significance of this posttranslational processing is uncertain. After reaching the plasma membrane, a variable proportion of TSHRs are cleaved into two subunits linked by disulfide bonds: the ligandbinding extracellular $\alpha$ (or A) subunit and the $\beta$ (or $B$ ) subunit, which consists of the remaining transmembrane and cytoplasmic tail that serves in signal transduction $(2,3)$. When forming this two-subunit structure, TSHR loses a polypeptide region following intramolecular cleavage (4) that may be secondary to progressive digestion of this segment (5). This intramolecular cleavage has been shown to remove an insertion of 50 amino acids (residues 317-366) unique to TSHR when compared with other glycoprotein receptors (6). Subsequently, shedding of the extracellular $\alpha$ subunit (7) is thought to follow reduction of the disulfide bonds (5). In addition, recent hypothesized models explaining TSHR activation have involved constitutive activity of the TSHR $\beta$ subunit being suppressed by the extracellular $\alpha$ subunit $(8,9)$. It is thought that ligand binding may change the conformation of the $\alpha$ subunit (9) or else a primary conformational change occurs in the $\alpha$ subunit to allow TSH ligand to bind (8). In either case, a conformational change in the TSHR $\alpha$ subunit plays a key role in TSHR activation.

Another part of posttranslational processing of TSHR involves multimerization. We recently demonstrated that TSHR constitutively takes on multimeric forms when seen by the fluorescent resonance energy transfer technique (10). We have also shown that these TSHR multimers dissociated into monomeric forms in response to TSH binding (11). This ligandinduced monomer formation was specific to the natural ligand TSH, since monoclonal TSHR-Ab's with thyroidblocking activity failed to mimic TSH and showed no monomer formation 
(R. Latif et al., unpublished data). Since the serum concentration of stimulating TSHR-stimulating antibody in Graves patients is low $(12,13)$, we have not been able to examine the influence of TSHR-stimulating antibodies on TSHR oligomeric forms using sera from patients with Graves disease.

Since the early claim of "cloning" of transient IgG monoclonal stimulating and blocking TSHR-Ab (14), obtained by transforming peripheral blood $\mathrm{B}$ cells from Graves patients with Epstein-Barr virus, several investigators have also claimed cloning of TSHR-stimulating monoclonal antibody (15-18). However, these thyroidstimulating activities were only achieved by high concentrations of IgG and some reports even lacked proof of specific TSHR antigen recognition. Furthermore, as mentioned earlier, the serum concentration of TSHR-Ab in Graves patients is low, as demonstrated by neutralization of TSHR-Ab with nanogram amounts of TSHR ectodomain protein (13). Therefore, the frequency of TSHR-Absecreting $B$ cells in these patients is also very low.

To obtain a true TSHR-stimulating monoclonal antibody, several animal models of Graves disease have been generated in recent years (19-22). To date, murine monoclonal TSHR-Ab's generated from these models have been shown to recognize the native conformation of TSHR, but all have been without thyroid-stimulating activity (20). We have therefore been attempting to generate a highly potent monoclonal antibody that would serve as a molecular probe and have therapeutic potential as a thyroid stimulator. Here we report such a potent TSHR-stimulating antibody generated from a new model of Graves disease based on the Armenian hamster.

\section{Methods}

Cells and virus. Chinese hamster ovary cells stably expressing human thyrotropin receptor (CHO-hTSHR cells or JPO9 cells) (23) and control CHO cells lacking hTSHR (CHO cells or JPO2 cells) were kindly provided by $\mathrm{G}$. Vassart, Louvain Medical School, Brussels, Belgium. Our CHO cell line stably expressing murine TSHR
(mTSHR) was also used (cDNA encoding MTSHR was kindly provided by P. Kopp, Northwestern University, Chicago, Illinois, USA). These cells were maintained in Ham's F12 medium (Mediatech Inc., Herndon, Virginia, USA) supplemented with $10 \%$ FBS (Mediatech Inc.), $100 \mathrm{U} / \mathrm{ml}$ penicillin, $100 \mathrm{U} / \mathrm{ml}$ streptomycin (Invitrogen Corp., Grand Island, New York, USA), and $400 \mu \mathrm{g} / \mathrm{ml}$ of geneticin (Invitrogen Corp.) at $37^{\circ} \mathrm{C}$ in $5 \% \mathrm{CO}_{2}$. An adenovirus vector incorporating full-length hTSHR (AdTSHR) was propagated, purified, and measured as previously reported (22).

Animals and immunization protocol. Graves disease was induced in 6- to 8week-old female Armenian hamsters $(n=10)$ purchased from Cytogen Research and Development Inc. (West Roxbury, Maine, USA). All animals were immunized intramuscularly with $5 \times 10^{11}$ particles of the adenovirus construct AdTSHR three times, 3 weeks apart, in the same way as described for mice (22). Blood thyroxine levels were measured by a neonatal paper assay (Diagnostic Products Corp., Los Angeles, California, USA). Hybridoma fusion and cloning of monoclonal TSHR-Ab's. Two hyperthyroid hamsters were selected to generate monoclonal antibodies against TSHR antigen. Three days before the fusion, these animals were boosted intraperitoneally with $1 \times 10^{7} \mathrm{CHO}$-hTSHR cells after treatment with $1 \mathrm{mg} / \mathrm{ml}$ of mitomycin C (Roche Molecular Biochemicals, Indianapolis, Indiana, USA) in Ham's $\mathrm{F} 12$ at $37^{\circ} \mathrm{C}$ for 2 hours, along with $50 \mu \mathrm{l} \mathrm{CFA} \mathrm{(Sigma-Aldrich,}$ St. Louis, Missouri, USA). Animals were sacrificed, and in separate experiments, spleen cells were fused to murine SP-02 cells (American Type Culture Collection, Rockville, Maryland, USA). Hybridoma fusions were performed as previously described (24). In brief, fused cells were maintained in selective Iscove's modified Dulbecco's medium (Invitrogen Corp.) containing 10\% FCS and supplements (gentamicin, L-glutamine, sodium pyruvate, and hypoxanthine/aminopterin/thymidine). About 2 weeks after fusion, supernatants were collected and screened by flow cytometer using CHO-hTSHR cells (see below). Positive clones were retested and only supernatants retesting positive were further recloned by limiting dilution to obtain a single clone. The concentration of hamster monoclonal IgG antibody, MS-1 and TAb-4, TAb-6, TAb-8, and TAb-16 in the hybridoma supernatants was determined by an IgG capture ELISA. Microtiter plates (Immulon 1; Dynatech Laboratories Inc., Chantilly, Virginia, USA) were coated with $1 \mu \mathrm{g} /$ well of purified anti-hamster IgG (Roche Molecular Biochemicals) in carbonate/bicarbonate buffer, $\mathrm{pH}$ 9.6, overnight at $4{ }^{\circ} \mathrm{C}$. A hamster monoclonal antibody of known concentration, purified on a protein A column from serum-free culture medium (Cell MAb Medium; BD Biosciences, Sparks, Maryland, USA), was used to generate a standard curve from $10 \mathrm{ng} / \mathrm{ml}$ to 100 $\mu \mathrm{g} / \mathrm{ml}$. Fifty microliters of hybridoma supernatant was added in duplicate. Captured hamster IgG was probed with anti-Armenian hamster IgG conjugated with biotin (1:250; BD Pharmingen, San Diego, California, USA), followed by streptavidin-conjugated alkaline phosphatase (1:500; Sigma-Aldrich). The unknown IgG concentration was calculated from the standard curve obtained by the control monoclonal antibody.

Detection of TSHR-Ab by flow cytometry. To determine TSHR-Ab in hybridoma supernatants, CHO-hTSHR cells were detached using $1 \mathrm{mM}$ EDTA/EGTA/ PBS (Sigma-Aldrich) and resuspended with PBS containing $0.1 \%$ BSA plus $0.01 \%$ sodium azide (FACS buffer). This suspension was distributed into roundbottom 96-well plates at $2 \times 10^{5}$ cells/well. Twenty-five microliters of hybridoma supernatants was added to each well and mixed. After 1 hour of incubation at $4^{\circ} \mathrm{C}$, cells were washed, and $50 \mu \mathrm{l}$ of FACS buffer containing $1: 100$ anti-Armenian hamster IgG (which reacts with $\left.\mathrm{IgG}_{1-3}\right) \quad(\mathrm{BD}$ Pharmingen) was incubated for 60 minutes at $4^{\circ} \mathrm{C}$ in the dark. Fluorescence intensity was measured by FACScan flow cytometer (BD Pharmingen). The positive clones were retested using CHO-hTSHR and control CHO cells using the same protocol. Only stable, specific clones developed stronger staining with CHO-hTSHR cells than 
Table 1

Autoimmune profiles of the two Armenian hamsters used for hybridoma fusion

\begin{tabular}{|c|c|c|c|c|c|c|c|}
\hline \multirow{3}{*}{ Hamster } & \multicolumn{6}{|c|}{ TSHR-Ab } & \multirow{3}{*}{$\begin{array}{l}\text { Thyroid } \\
\text { hypertrophy }\end{array}$} \\
\hline & T4 & Competition & \multicolumn{2}{|c|}{ Stimulation (\%) } & \multicolumn{2}{|c|}{ FACS $^{A}$} & \\
\hline & $(\mu \mathrm{g} / \mathrm{dl})$ & (\%) & hTSHR & mTSHR & $\begin{array}{c}\operatorname{lgG}_{2} \\
\text { and } \lg G_{3}\end{array}$ & $\operatorname{lgG}_{1}$ & \\
\hline $\begin{array}{l}1 \\
2\end{array}$ & $\begin{array}{l}7.7 \\
4.6\end{array}$ & $\begin{array}{l}\mathbf{9 9 . 1} \pm 1.3 \\
\mathbf{9 4 . 0} \pm 6.2\end{array}$ & $\begin{aligned} 95 & \pm 9.8 \\
1,359 & \pm 52.7\end{aligned}$ & $\begin{array}{l}230 \pm 24.6 \\
852 \pm 7.0\end{array}$ & $\begin{array}{l}50.4 \\
59.3\end{array}$ & $\begin{array}{l}1.9 \\
3.0\end{array}$ & $\begin{array}{l}+ \\
+\end{array}$ \\
\hline Preimmune & $<3.5$ & $0.0 \pm 2.3$ & $100 \pm 14.3$ & $100 \pm 4.6$ & 3.3 & 4.6 & \\
\hline
\end{tabular}

Blood thyroxine (T4) levels higher than $3.5 \mu \mathrm{g} / \mathrm{dl}$ (mean $+3 \mathrm{SD}$ s of preimmune animals; $n=10$ ) were considered abnormal. Competition column shows binding inhibition of labeled TSH to TSHR on CHOhTSHR cells (expressing human TSHR) by TSHR-Ab, expressed as percent competition compared with preimmune serum. Stimulation column shows cAMP production by TSHR-Ab on either CHO-hTSHR or $\mathrm{CHO}$-mTSHR cells (expressing mouse TSHR), expressed as percent stimulation compared with preimmune serum. More than $15 \%$ competition and more than $200 \%$ stimulation were judged as positive assay (shown in bold). ${ }^{A}$ Each value indicates the mean fluorescence intensity on CHO-hTSHR cells. Mean $\pm 3 \mathrm{SD}$ s of the fluorescence intensity on $\mathrm{CHO}$ cells stained by each serum was less than 4.5 on $\operatorname{lgG}_{2}$ and $\lg G_{3}$ and less than 5.0 with $\lg G_{1}$.

with $\mathrm{CHO}$ cells and were judged as positive and subjected to limiting dilution. When hamster serum was examined, serum was diluted 1:100 with FACS buffer and incubated with either $\mathrm{CHO}$ hTSHR or CHO cells. Anti-Armenian hamster $\operatorname{IgG}_{2}$ and $\operatorname{IgG}_{3}$ conjugated with FITC and anti-Armenian hamster $\operatorname{IgG}_{1}$ conjugated with biotin (BD Pharmingen) were used as secondary antibodies. Streptavidin-conjugated phycoerythrin (1:100; Sigma-Aldrich) was used to obtain two-color staining to determine the IgG isotype of TSHR-Ab's.

Detection of TSHR-Ab by competition assay. CHO-TSHR cells $\left(5 \times 10^{4}\right)$ were seeded into 96-well plates 1 day prior to assay. All assays were performed in triplicate. The next day, the cells were washed with modified Hanks' solution (5.4 mM KCl, $1.31 \mathrm{mM} \mathrm{CaCl}_{2} 2 \mathrm{H}_{2} \mathrm{O}, 0.8$ $\mathrm{mM} \mathrm{MgSO}_{4} 7 \mathrm{H}_{2} \mathrm{O}, 0.3 \mathrm{mM} \mathrm{Na}_{2} \mathrm{HPO}_{4}$,
$0.4 \mathrm{mM} \mathrm{KH}_{2} \mathrm{PO}_{4}, 33.5 \mathrm{mM}$ HEPES, 1 $\mathrm{g} / \mathrm{l}$ of dextrose, and $0.2 \%$ BSA). Cells were then incubated with $50 \mu \mathrm{l}$ of modified Hanks' solution containing increasing doses of bovine TSH (specific activity, $2.0 \mathrm{IU} / \mathrm{mg}$; Sigma-Aldrich) for generating a standard curve, or $50 \mu \mathrm{l}$ of a supernatant, or $50 \mu \mathrm{l}$ of 1:10 serum plus $50 \mu \mathrm{l}$ of ${ }^{125}$ I-labeled TSH (Kronus Inc., Boise, Idaho, USA) containing $10,000 \mathrm{cpm} /$ well at $37^{\circ} \mathrm{C}$ for 2 hours. The radioactivity remaining on $\mathrm{CHO}-$ hTSHR cells after three washings was measured following cell lysis in $1 \mathrm{~N}$ $\mathrm{NaOH}$. Percent competition was determined as the ratio of the competition by the test specimen to the competition by the culture medium. Based on previous experience, control supernatants gave less than $15 \%$ inhibition.

Detection of stimulating and blocking TSHR-Ab. CHO-hTSHR cells were seeded at $4 \times 10^{4}$ cells per well on 96 well plates a day prior to the assay. All assays were performed in triplicate in the absence of any phosphodiesterase inhibitors. To stimulate CHO-hTSHR, hybridoma supernatant $(20 \mu \mathrm{l})$ was diluted 1:5 with fresh medium and incubated with cells at $37^{\circ} \mathrm{C}$ for 2 hours. Medium was discarded and intracellular cyclic AMP (cAMP) was measured by ELISA according to the manufacturer's protocol (Amersham Pharmacia Biotech, Newark, New Jersey, USA). Stimulation was expressed as the percent increase in cAMP production by hybridoma supernatant divided by cAMP production by medium. Based on previous experience, control supernatants gave less than $200 \%$ stimulation. To study hamster serum, stimulation was performed similarly, except sera were diluted 1:10 with fresh medium. A similar protocol was used to detect blocking TSHR-Ab. CHO-hTSHR cells were incubated with $20 \mu$ l of hybridoma supernatants in addition to $80 \mu \mathrm{l}$ of fresh medium containing $125 \mu \mathrm{U} / \mathrm{ml}$ of bovine TSH (final concentration of TSH was 100 $\mu \mathrm{U} / \mathrm{ml})$. Blocking was expressed as the percent reduction of cAMP produced by test supernatant divided by cAMP produced by medium. Normal control antibody supernatants caused less than $20 \%$ blocking in this assay.

Determination of IgG isotype of monoclonal antibody. The IgG isotype of TSHR monoclonal antibodies was determined using a combination of commercial monoclonal antibodies

Table 2

Characterization of monoclonal TSHR-Ab

\begin{tabular}{|c|c|c|c|c|c|c|c|c|c|c|c|}
\hline \multirow[t]{2}{*}{ Hamster $^{\mathrm{A}}$} & \multirow{2}{*}{$\begin{array}{l}\text { Name } \\
\text { (clone) }\end{array}$} & \multirow{2}{*}{$\begin{array}{l}\operatorname{lgG} \\
\text { isotype }\end{array}$} & \multirow{2}{*}{$\begin{array}{c}\text { Competition } \\
(\%)\end{array}$} & \multirow{2}{*}{$\begin{array}{c}\text { Stimulation } \\
(\%)\end{array}$} & \multicolumn{2}{|c|}{ Blocking ${ }^{B}$} & \multicolumn{5}{|c|}{ Epitope assay } \\
\hline & & & & & cAMP & (\%) & Peptide ${ }^{C}$ & Unfixed & NC35 & $\beta^{\mathrm{D}}$ & Fixed cell \\
\hline 1 & MS-1 (4G10) & $\lg G_{2}$ & $84 \pm 3.5$ & $1,275 \pm 0.0$ & $314 \pm 18.9$ & (83.1) & $\mathrm{N}$ & $\mathrm{Y}$ & $\mathrm{Y}$ & $\mathrm{N}$ & $\mathrm{N}$ \\
\hline 2 & TAb-4 (3D9) & $\lg _{2}$ & $10 \pm 4.2$ & $195 \pm 10.9$ & $1,341 \pm 15.6$ & $(43.3)$ & $316-335$ & Y & $\mathrm{N}$ & $\mathrm{N}$ & $\mathrm{N}$ \\
\hline 2 & TAb-6 (4A3) & $\lg _{2}$ & $9 \pm 11.7$ & $142 \pm 14.2$ & $2,179 \pm 87.2$ & $(7.8)^{\prime}$ & $316-335$ & $\mathrm{Y}$ & $\mathrm{N}$ & $\mathrm{N}$ & $\mathrm{N}$ \\
\hline 2 & TAb-8 (7F9) & $\lg G_{2}$ & $91 \pm 9.2$ & $136 \pm 8.6$ & $441 \pm 20.7$ & (81.4) & $\mathrm{N}$ & $\mathrm{Y}$ & $\mathrm{Y}$ & $\mathrm{N}$ & $\mathrm{N}$ \\
\hline 2 & TAb-16 (2F10) & $\operatorname{lgG}_{2}$ & $4 \pm 12.7$ & $112 \pm 6.6$ & $2,506 \pm 41$ & $(0.0)$ & $301-320$ & $Y$ & $\mathrm{~N}$ & $\mathrm{~N}$ & $\mathrm{~N}$ \\
\hline & Medium & & $<15$ & $100 \pm 5.3$ & $90 \pm 8.3$ & $(100.0)$ & & & & & \\
\hline & $\mathrm{SH}(100 \mu \mathrm{U} / \mathrm{ml})$ & & $13 \pm 6.2$ & $2,000 \pm 42$ & $2,362 \pm 55.6$ & $(0.0)$ & & & & & \\
\hline
\end{tabular}

Summary of five monoclonal TSHR-Ab's is shown. Concentration of each antibody was: MS-1, $10 \mu \mathrm{g} / \mathrm{ml}$; TAb-4, $5 \mu \mathrm{g} / \mathrm{ml}$; TAb- $6,3 \mu \mathrm{g} / \mathrm{ml} ; \mathrm{TAb}-8,5 \mu \mathrm{g} / \mathrm{ml}$; and TAb-16, $50 \mu \mathrm{g} / \mathrm{ml}$. Competition column shows inhibition of binding of labeled TSH to TSHR on CHO-hTSHR cells by TSHR-Ab, expressed as percent competition compared with fresh medium. Stimulation column shows cAMP production by TSHR-Ab on CHO-hTSHR cells, expressed as percent stimulation compared with fresh medium. More than $15 \%$ competition, greater than $200 \%$ stimulation, and greater than $20 \%$ blockade was judged as positive assay (shown in bold). AHamster numbers correspond to the animals shown in Table 1. BShown are cAMP produced (in fmol/well) followed in parentheses by percent blocking, expressed as a percentage of the value obtained with TSH alone. In the case of MS-1, cAMP produced by MS- 1 alone was subtracted from cAMP produced by MS- 1 plus TSH. CImmunoreactivity against each human TSHR peptide residue sequence was only marginal. ${ }^{\circ} \beta$ column shows TSHR variants, including all $\beta 316, \beta 366$, and $\beta 409$ cells expressing TSHR $\beta$-subunits beginning with residue 316,366 , and 409 , respectively. $Y$ and $N$ indicate positive reaction and negative reaction, respectively. 


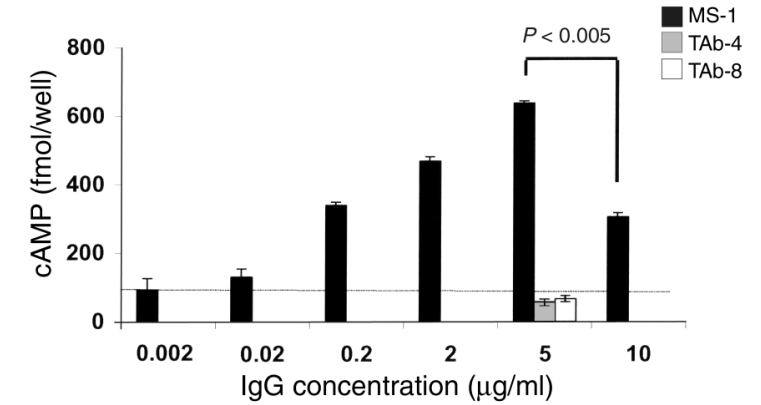

Figure 1

cAMP dose-response study of TSHR-stimulating monoclonal antibody MS-1. MS-1 was examined for thyroid-stimulating activity at the indicated concentrations. TAb- 4 and TAb- $8(5 \mu \mathrm{g} / \mathrm{ml})$ were used as negative controls. Thyroid stimulation was expressed as a ratio with basal cAMP levels induced by culture medium. More than $200 \%$ stimulation above baseline was judged as positive and is shown as a dotted line.

against Armenian hamster $\operatorname{IgG}_{1}, \mathrm{IgG}_{2}$, and $\mathrm{IgG}_{2}$ and $\mathrm{IgG}_{3}$ (BD Pharmingen) as secondary antibodies on flow cytometry with CHO-hTSHR cells. $\mathrm{IgG}_{2}$ and $\mathrm{IgG}_{3}$ isotypes were determined by positive $\operatorname{IgG}_{2}$ and positive $\mathrm{IgG}_{2}$ and $\mathrm{IgG}_{3}$, and negative $\mathrm{IgG}_{2}$ and positive $I g G_{2}$ and $I g G_{3}$, respectively.

Epitope analysis of monoclonal TSHR antibodies. Linear epitopes were detected using hTSHR peptides as previously described (25). In brief, hTSHR peptides, kindly provided by J. Morris (Mayo Medical School, Rochester, Minnesota, USA) (26), were used to coat 96well microtiter plates as for the IgG assay. Fifty microliters of hybridoma supernatants were added, and color was developed using the same reagents as in the hamster IgG determination. To examine whether or not monoclonal antibodies recognized conformational epitopes of TSHR antigen, $\mathrm{CHO}-$ hTSHR cells were fixed with $4 \%$ paraformaldehyde/PBS (Sigma-Aldrich) at room temperature for 10 minutes. After cells were washed twice, monoclonal antibody was incubated and fluorescence intensity was measured by flow cytometry. Control CHO cells were also fixed to serve as a negative control. CHO cells stably expressing TSHR variants tagged with green fluorescent protein (GFP) were also used to map the epitopes. NC35 cells with uncleavable TSHR-GFP expressed a TSHR lacking the 50-amino-acid insertion, residues 317-366 (27) (cDNA kindly provided by B. Rapoport, University of California, Los Angeles, Los Angeles, California, USA). TSHR tagging was described pre- viously (10). Our $\beta 316, \beta 366$, and $\beta 409$ cells expressed only TSHR $\beta$ subunits beginning with residues 316,366 , and 409. These TSHR $\beta$-variant cells were obtained using PCR-amplified products from full-length TSHR cDNA in pBluescript SK+ (Stratagene, La Jolla, California, USA) as the template. A single reverse primer corresponding to the TSHR carboxyl terminus was used in each case (5'-CATAGGCGCCGCCCAGGTCCCTGGGCACGTCGAG-3'). Three forward primers (5'-CATAGGCGCCTTGAATAGCCCCCTCCACCAGGAA-3'; 5'-CATACCCGGGCAGGAGCTCAAAAACCCCCAGGAA-3'; and 5'-GAAGACATAATGGGCTACAAGTTCCTGAGA-3') with added restriction enzyme sites were used to generate the TSHR $\beta$ subunits beginning with residues 316,366 , and 409 . The restricted products were ligated inframe to the $3^{\prime}$ end of the TSHR signal peptide cDNA generated by annealing forward and reverse signal peptide
Figure 2 oligonucleotides. Sequences were verified by direct sequencing. Each truncated TSHR $\beta$ subunit was then cloned into pEGFP-N1 (Clontech Laboratories Inc., Palo Alto, California, USA). For cloning, stop codons at the $3^{\prime}$ end of the insert were omitted and the modified inserts were ligated in-frame to the amino-terminus of GFP. These cells were all similarly stained with monoclonal antibodies, and immunoreactivity was studied by flow cytometry. For Western blotting, cell membrane preparations made using digitonin from CHO-hTSHR cells (28), and TSHR ectodomain protein (TSHR-289) (13) (kindly provided B. Rapoport) were separated by SDS-PAGE under reducing conditions (with $2 \% \beta$-mercaptoethanol) and transferred to PVDF membrane (Pall Corp., Ann Arbor, Michigan, USA). Hybridoma supernatant (1:5 dilution) was used as primary antibody. Antihamster IgG conjugated with horseradish peroxidase (BD Pharmingen) was used as secondary antibody.

TSHR cleavage determined by flow cytometry. To quantify TSHR cleavage, two monoclonal TSHR antibodies were used. RSR-4 recognizes residues 322-341, an epitope within the 50amino-acid insertion (4) that is lacking in the cleaved TSHR. RSR-1 recognizes an epitope on the $\mathrm{N}$-terminus of the $\beta$ subunit of TSHR. RSR-1 and RSR-4 (29) were kindly provided by B. Rees Smith (RSR Ltd., Cardiff, United Kingdom). CHO-hTSHR cells were seeded at $0.8 \times 10^{6}$ cells per well in six-well plates with $10 \%$ serum containing cell culture medium in the presence of various doses of bovine TSH (total volume

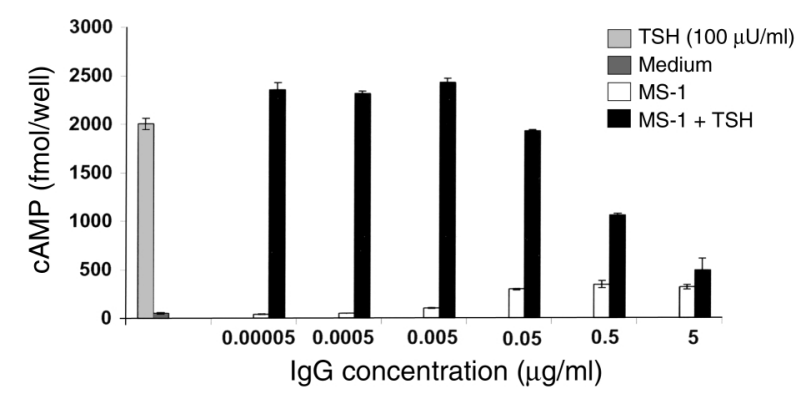

Dose-response study of the blocking activity of MS-1. CHO-hTSHR cells were stimulated with MS-1 at the indicated concentrations with or without $100 \mu \mathrm{U} / \mathrm{ml}$ of TSH. Since MS- 1 is a TSHR-stimulating monoclonal antibody, the CAMP generated by MS-1 alone was subtracted from the CAMP generated by MS-1 plus TSH. Medium alone produced less than 50 fmol/well cAMP, and TSH $(100 \mu \mathrm{U} / \mathrm{ml})$ generated 2,000 fmol/well. 

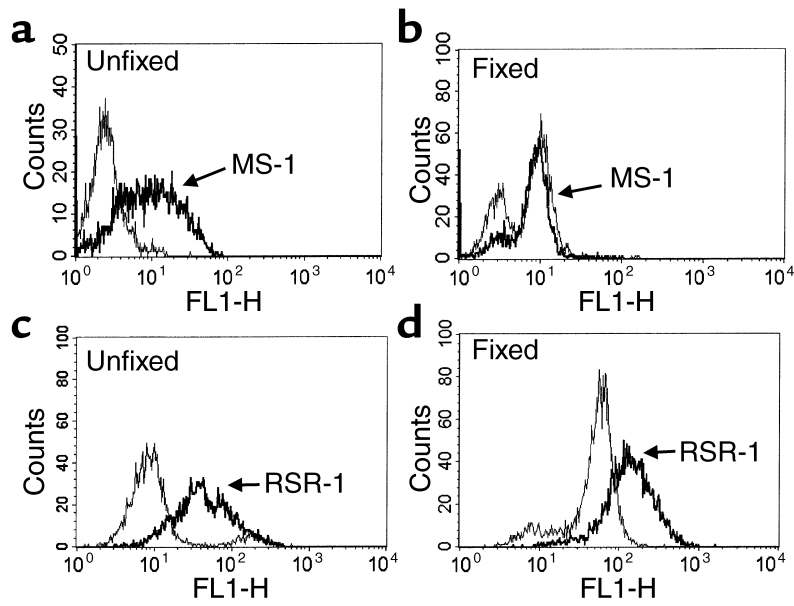

Figure 3

Recognition of a TSHR conformational epitope by MS-1. MS-1 recognized the native conformation of hTSHR antigen on unfixed CHO-hTSHR cells (a), but not on fixed CHO-hTSHR cells (b). In contrast to MS-1, mouse monoclonal TSHR-Ab RSR-1 (29) recognized both the native (c) and fixed (d) conformations of the hTSHR. Thin and thick lines indicate staining on $\mathrm{CHO}$ and $\mathrm{CHO}-\mathrm{hTSHR}$ cells, respectively. Fluorescence intensity was measured in FL-1.
$2 \mathrm{ml}$ ) and incubated for 24 hours at $37^{\circ} \mathrm{C}$. After being washed twice in PBS and detached, CHO-hTSHR cells were RSR antibodies $(1 \mu \mathrm{g} /$ sample). Antimouse IgG conjugated with phycoerythrin (1:100; Sigma-Aldrich) was used as secondary antibody.

Statistical analysis. The Student $t$ test was used for statistical analysis. $P<0.05$ was considered significant.

\section{Results}

Immunization. Among ten hamsters immunized with adenovirus vector, two were chosen for hybridoma fusion. Autoimmune profiles of thyroxine levels and TSHR-Ab's from these two animals are shown in Table 1 . The sera contained mainly $\mathrm{IgG}_{2}$ and $\mathrm{IgG}_{3}$ TSHR-Ab as determined by flow cytometry, suggesting that these hyperthyroid animals predominantly had a Th1 immune response (30). TSHR-Ab in the serum detected by competition assay showed more than $90 \%$ blocking of labeled TSH binding. The presence of stimulating TSHR-Ab was also detectable in these sera, one serum stimulated both human and mouse TSHR-expressing $\mathrm{CHO}$ cells and one serum stimulated only the mouse TSHR (Table 1). The thyroid specimens from these two animals showed thyroid cell hypertrophy associated with papillary protrusions (not shown). aliquoted and stained with the above
Screening and isolation of monoclonal TSHR-Ab. In total, 1,920 wells were screened by flow cytometry using CHO-hTSHR cells, and 39 positive supernatants were selected. These positive supernatants were retested to eliminate unstable clones. Seven of the 39 supernatants were stably positive and were then recloned by limiting dilution to obtain single clones. Out of these seven, five monoclonal TSHRAb's were available for further analysis (Table 2). The IgG isotype of these seven monoclonal antibodies was
$\mathrm{IgG}_{2}$, reflecting the $\operatorname{IgG}$ serum isotype of the hyperthyroid animals.

Functional assay of monoclonal TSHR$A b$. Monoclonal antibodies MS- 1 and TAb- 8 showed greater than $80 \%$ competition for ${ }^{125}$ I-labeled TSH binding, but no competition was observed with the other three monoclonal antibodies (Table 2). In the cAMP bioassay, MS-1 induced approximately 13 times more cAMP production in CHO-hTSHR cells ( $27 \pm 16$ vs. $346 \pm 0.0 \mathrm{fmol})$ and seven times more in CHO-mTSHR cells $(12 \pm 3.2$ vs. $84.3 \pm 19.2 \mathrm{fmol})$ than was seen in fresh medium. No increase in cAMP production was seen with control CHO cells (from $17.6 \pm 2.6$ to $12.2 \pm 0.4 \mathrm{fmol}$ with $2.5 \mu \mathrm{g} / \mathrm{ml} \mathrm{MS}-1$ ). In the presence of $100 \mu \mathrm{U} / \mathrm{ml} \mathrm{TSH}$, MS-1 and TAb-8 blocked TSH-induced cAMP production. Thus, MS-1 was a monoclonal TSHR-Ab that competed for TSH binding and induced thyroid stimulation. MS-1 was also able to occupy TSHR and block further TSH activity. In contrast, TAb- 8 competed for TSH binding and had TSH-blocking activity but no thyroid-stimulating activity. TAb-4 showed only TSH blocking activity, while TAb- 6 and TAb-16 were neutral TSHR antibodies. To date, MS- 1 has been in culture in our lab for 3 months and has been recloned on three occasions and has maintained its stability.

MS-1 was further studied to determine the potency of its thyroid-stim-
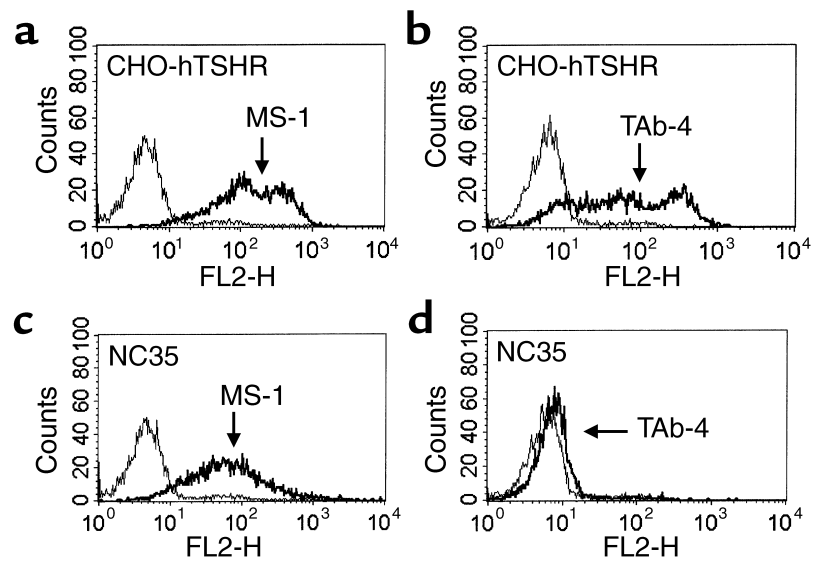

\section{Figure 4}

Epitope recognition within TSHR residues 317-366 by TAb-4, but not MS-1. MS-1 reacted similarly to both CHO-hTSHR (a) and NC35 (c) cells. However, strong immunoreactivity seen on CHO-hTSHR cells (b) by TAb-4 was lost on NC35 cells (d) lacking TSHR residues 317-366. The thick lines indicate CHO-hTSHR cells in $\mathbf{a}$ and $\mathbf{b}$, and NC35 cells in $\mathbf{c}$ and $\mathbf{d}$. The thin lines indicate $\mathrm{CHO}$ cells. Fluorescence intensity was measured in FL-2. 


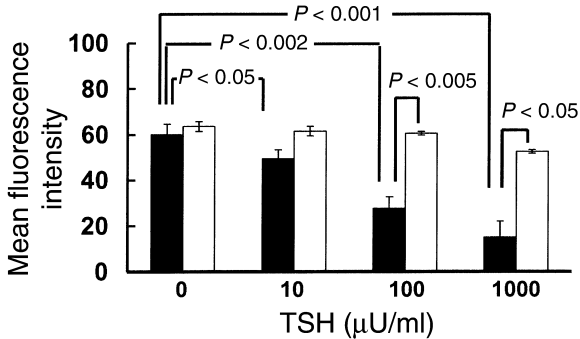

Figure 5

TSHR cleavage assay. CHO-hTSHR cells were treated with increasing concentrations of TSH for 24 hours and stained with two monoclonal TSHR-Ab's in order to examine the effect of TSH on TSHR cleavage. RSR- 1 (white bars) recognized the $\beta$ subunit of TSHR, in contrast to the recognition of the region subjected to receptor cleavage (residues 317-366) by RSR-4 (black bars). It should be noted that RSR-4 had no TSH-competing activity. Reduction of immunoreactivity by RSR-4 was a measure of TSHR cleavage and was observed after treatment with TSH (more than $10 \mu \mathrm{U} / \mathrm{ml})$.

ulating and blocking activity. As shown in Figure 1, cAMP production more than two times higher than basal cAMP was seen at MS- 1 concentrations down to about $20 \mathrm{ng} / \mathrm{ml}$. Interestingly, this activity had a peak around $5 \mu \mathrm{g} / \mathrm{ml}$, and at a higher concentration $(10 \mu \mathrm{g} / \mathrm{ml})$, thyroid-stimulating activity was significantly decreased $(P<0.005)$. The TSHblocking activity of MS-1, secondary to TSHR occupancy, was further assessed in a serial dilution study (Figure 2). Since MS-1 is a TSHRstimulating monoclonal antibody, the cAMP generated under the stimulation of $100 \mu \mathrm{U} / \mathrm{ml} \mathrm{TSH}$ was the sum of the cAMP generated by TSH and MS-1. As shown in Figure 2, with simultaneous stimulation by TSH, MS-1 inhibited the enhanced generation of cAMP induced by the addition of TSH. This interference with TSH stimulation was seen down to approximately $500 \mathrm{ng} / \mathrm{ml}$.

Epitope determination of monoclonal antibodies. In a linear epitope assay using human TSHR peptides, no major epitopes of these monoclonal antibodies were determined. However, there was a low degree of immunoreactivity seen with peptides corresponding to residues $316-335$ with TAb-4 and TAb- 6 and at residues 301-320 with TAb-16 (Table 2). Since the five monoclonal TSHR-Ab's were selected by recognition of TSHR expressed on CHO-hTSHR cells in its native conformation, it was not unexpected that they would have no significant recognition of TSHR peptides. The antibod- ies were also further tested with fixed CHO-hTSHR cells on which TSHR antigen would be expected to lose its native conformation. As shown in Figure 3 , strong staining of CHO-hTSHR by MS-1 (Figure 3a) was lost after fixation (Figure $3 \mathrm{~b}$ ), confirming that MS-1 recognized a conformational epitope of TSHR. Other antibodies similarly lost their reactivity on fixed CHOhTSHR cells (Table 2). It should be noted that this procedure did not eliminate TSHR antigen on CHO-hTSHR cells, since mouse monoclonal antibody RSR-1 (which recognizes linear residues 381-385) (29) clearly showed immunoreactivity with both unfixed and fixed CHO-hTSHR cells (Figure 3,
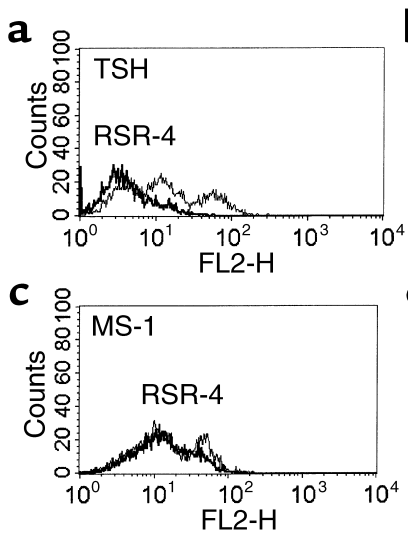

\section{Figure 6} and $\mathbf{b}$ ) and MS-1 (c and d), respectively. $c$ and $d$, respectively). These data were also supported by the absence of reactivity on Western blots (data not shown). Thus, all of these monoclonal antibodies recognized conformational epitopes of TSHR antigen.

To further study the possible epitopes of these monoclonal antibodies, four $\mathrm{CHO}$ cell lines stably expressing variants of hTSHR were used. NC35 cells expressed an uncleavable TSHR following deletion of TSHR residues 317-366 (27). Our $\beta 316, \beta 366$, and $\beta 409$ cells expressed only TSHR $\beta$ subunits beginning with residues 316 , 366 , and 409, respectively. Among the monoclonal antibodies examined, none recognized the TSHR $\beta$-variant proteins (Table 2). In contrast, MS-1 (Figure 4c) and TAb-8 (Table 2) recognized TSHR antigen expressed on NC35 cells, but the other monoclonal antibodies did not (Table 2). These data indicated that conformational epitopes recognized by monoclonal antibodies MS- 1 and TAb- 8 were more likely on the TSHR $\alpha$ subunit, and that TAb-4, TAb-6, and TAb-16 could not bind in the absence of TSHR residues 317-366, the polypeptide region subjected to TSHR cleavage. Since deletion of this amino acid insertion of TSHR did not reduce the immunoreactivity of MS-1 (Figure 4, a and c) or TAb-8 (Table 2) the conformational epitopes of these mono-
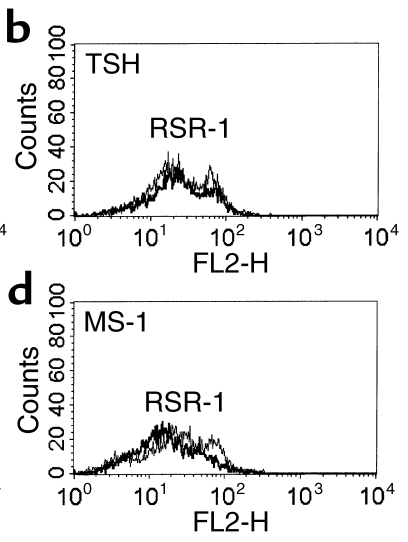

TSHR cleavage is not induced by MS-1. CHO-hTSHR cells were treated with $100 \mu \mathrm{U} / \mathrm{ml}$ ofTSH for 24 hours and stained with two monoclonal TSHR-Ab's, and showed a reduction in the immunoreactivity of RSR-4 (a) but not RSR-1 (b). In contrast, similar treatment with MS-1 (5 $\mu \mathrm{g} / \mathrm{ml}$ ) did not alter immunoreactivity by either RSR-4 (c) or RSR-1 (d), indicating that MS-1 did not accelerate TSHR cleavage. The thin lines indicate staining of CHO-hTSHR cells without TSH ( $\mathbf{a}$ and $\mathbf{b}$ ) or MS-1 (c and $\mathbf{d})$, and thick lines indicate CHO-hTSHR cells with TSH (a 
clonal antibodies did not involve this region. This observation was also compatible with previous studies showing that TSHR cleavage was not necessary for TSH binding or activation of $\operatorname{TSHR}(4,31)$. These data therefore also confirmed the low immunoreactivity we observed to the peptides representing the 50 amino acid residues deleted in NC35 cells (Table 2). We concluded that these two monoclonal antibodies, MS-1 and TAb-8, had major conformational epitopes that did not incorporate the cleavage region.

Induction of TSHR cleavage by TSH but not MS-1. TSHR is subject to posttranslational modifications, including intramolecular cleavage, that generate a two-subunit ( $\alpha$ or $A$, and $\beta$ or B) structure $(2,3)$ followed by shedding of the extracellular $\alpha$ subunit (7). We examined whether TSH and MS-1 had any effect on TSHR intramolecular cleavage by using a technique involving two monoclonal antibodies against the region subjected to the TSHR cleavage (RSR-4) and non-cleavage regions (RSR-1). Antibody specificity of RSR-4 was confirmed using CHO-hTSHR and NC35 cells by showing the presence of antibody binding on CHO-hTSHR, but not on NC35 cells (data not shown). RSR-1 has been shown to have a potent inhibitory effect on TSH binding, whereas RSR-4 showed no TSH competing activity (data not shown). Using these antibodies, we were able to quantify TSHR cleavage by flow cytometry. As shown in Figure 5 and Figure 6, TSH significantly reduced the binding of monoclonal antibody RSR-4 (Figure 6a), whereas no significant reduction was seen with the antibody against the non-cleavage region (Figure 6b). This reduction in immunoreactivity of RSR-4 was seen at all concentrations of TSH tested, and TSH appeared to enhance TSHR cleavage in a dose-dependent (Figure 5) and time-dependent manner detectable within 3 hours of exposure (data not shown). There was up to $75 \%$ inhibition of initial RSR-4 binding after treatment with $1,000 \mu \mathrm{U} / \mathrm{ml}$ of TSH (Figure 5). When MS-1 was tested for the enhancement of TSHR cleavage, none was observed (Figure
6, c and d). Thus, TSHR cleavage was specifically accelerated by TSH but not by stimulating TSHR-Ab.

\section{Discussion}

Here we report the successful cloning of a monoclonal TSHR antibody (MS-1) with potent thyroid-stimulating activity derived from a hamster immunized with an adenovirus vector incorporating full-length hTSHR (AdTSHR). This stimulating TSHR-Ab recognized a conformational epitope on the TSHR antigen and was a potent thyroid stimulator detectable with as little as $20 \mathrm{ng} / \mathrm{ml}$. This was consistent with the expectation that thyroid-stimulating antibody should be actively stimulatory at nanogram levels as determined by inactivation and absorption of TSHR-Ab in Graves patient serum using TSHR ectodomain protein (13). Interestingly, higher concentrations of MS-1 showed reduced activity as shown by a reduction in cAMP production. The mechanisms responsible for this reduction in potency remain to be determined but likely involve either downregulation or the development of receptor inactivation related to receptor multimerization, as we have previously suggested (1).

Each of the monoclonal antibodies examined in these studies recognized a conformational epitope on TSHR antigen as shown by a failure of antigen recognition after fixation. To further explore these epitopes, $\mathrm{CHO}$ cells stably expressing TSHR variants were used. From these studies, it was clear that MS- 1 and TAb- 8 recognized a conformational epitope involving the TSHR $\alpha$ subunit only, whereas TAb-4, TAb-6, and TAb-16 recognized conformational epitopes involving TSHR residues 317-366 (Table 2 and Figure 4) subjected to TSHR cleavage (27). We were also able to examine the influence of MS-1 on TSHR cleavage itself. We showed that TSH accelerated TSHR cleavage in a dose-dependent manner but then found that MS-1 did not mimic TSH action. Since the shedding of the TSHR ectodomain has been shown to follow TSHR cleavage (7), the binding of a TSHR-Ab such as MS-1 to TSHR would be expected not to accelerate this event, as would occur after TSH binding. Because TSH was apparently able to increase cleavage by almost $75 \%$, this failure by a TSHR-Ab was a dramatic departure from TSH action. Since TSHR cleavage is likely to also be followed by $\alpha$ subunit shedding (7) and receptor degradation (31), our data strongly suggested that since the stimulating TSHR-Ab did not exacerbate cleavage, there would likely be a delay in the degradation of TSHRs. Thus, the thyroid autoimmunity seen in Graves disease induced by stimulating TSHR$\mathrm{Ab}$ may involve a prolonged functional half-life for the target antigen in addition to the prolonged half-life of IgG itself. This difference may contribute to the prolonged overstimulation long known to be induced by TSHR-Ab's and not be simply secondary to the longer half-life of IgG (1).

In summary, we successfully isolated a TSHR-stimulating monoclonal antibody, MS-1, that had a marked thyroid-stimulating activity at nanogram concentrations. MS- 1 recognized a conformational epitope incorporating the $\alpha$ subunit of the native TSHR antigen but not involving the TSHR cleavage region. Furthermore, we also showed that while TSH accelerated TSHR cleavage into two subunits, MS-1 did not mimic this effect of TSH. These data suggested a novel mechanism to explain the prolonged overstimulation of the thyroid gland in Graves disease.

\section{Acknowledgments}

We thank Russell Marians for helpful advice and Ilaria Ciullo for preparing the TSHR $\beta$ subunit-expressing $\mathrm{CHO}$ cells. This work was supported in part by NIH grants DK-52464, DK-45011, and AI-24671 (to T.F. Davies), and by the David Owen Segal Endowment (to T. Ando).

1. Davies, T., Marians, R., and Latif, R. 2002. The TSH receptor reveals itself. J. Clin. Invest. 110:161-164. doi:10.1172/JCI200216234.

2. Loosfelt, H., et al. 1992. Two-subunit structure of the human thyrotropin receptor. Proc. Natl. Acad. Sci. USA. 89:3765-3769.

3. Rees Smith, B., McLachlan, S.M., and Furmaniak, J. 1988. Autoantibodies to the thyrotropin receptor. Endocr. Rev. 9:106-121.

4. Chazenbalk, G.D., et al. 1997. Evidence that the thyrotropin receptor ectodomain contains not one, but two, cleavage sites. Endocrinology. 138:2893-2899.

5. de Bernard, S., et al. 1999. Sequential cleavage and excision of a segment of the thyrotropin receptor ectodomain. J. Biol. Chem. 274:101-107.

6. Rapoport, B., Chazenbalk, G.D., Jaume, J.C., and McLachlan, S.M. 1998. The thyrotropin (TSH) 
receptor: interaction with TSH and autoantibodies. Endocr. Rev. 19:673-716.

7. Couet, J., et al. 1996. Shedding of human thyrotropin receptor ectodomain. Involvement of a matrix metalloprotease. J. Biol. Chem. 271:4545-4552.

8. Szkudlinski, M.W., Fremont, V., Ronin, C., and Weintraub, B.D. 2002. Thyroid-stimulating hormone and thyroid-stimulating hormone receptor structure-function relationships. Physiol. Rev. 82:473-502.

9. Vlaeminck-Guillem, V., Ho, S.C., Rodien, P., Vassart, G., and Costagliola, S. 2002. Activation of the cAMP pathway by the TSH receptor involves switching of the ectodomain from a tethered inverse agonist to an agonist. Mol. Endocrinol. 16:736-746.

10. Latif, R., Graves, P., and Davies, T.F. 2001. Oligomerization of the human thyrotropin receptor: fluorescent protein-tagged hTSHR reveals post-translational complexes. J. Biol. Chem. 276:45217-45224.

11. Latif, R., Graves, P., and Davies, T.F. 2002. Liganddependent inhibition of oligomerization at the human thyrotropin receptor. J. Biol. Chem. 9:9.

12. Jaume, J.C., Kakinuma, A., Chazenbalk, G.D., Rapoport, B., and McLachlan, S.M. 1997. Thyrotropin receptor autoantibodies in serum are present at much lower levels than thyroid peroxidase autoantibodies: analysis by flow cytometry. J. Clin. Endocrinol. Metab. 82:500-507.

13. Chazenbalk, G.D., Jaume, J.C., McLachlan, S.M., and Rapoport, B. 1997. Engineering the human thyrotropin receptor ectodomain from a nonsecreted form to a secreted, highly immunoreactive glycoprotein that neutralizes autoantibodies in Graves' patients' sera. J. Biol. Chem. 272:18959-18965

14. Valente, W.A., et al. 1982. Monoclonal antibodies to the thyrotropin receptor: stimulating and blocking antibodies derived from the lymphocytes of patients with Graves disease. Proc. Natl.
Acad. Sci. USA. 79:6680-6684.

15. Kohn, L.D., et al. 1997. Characterization of monoclonal thyroid-stimulating and thyrotropin binding-inhibiting autoantibodies from a Hashimoto's patient whose children had intrauterine and neonatal thyroid disease. J. Clin. Endocrinol. Metab. 82:3998-4009.

16. Li, H., et al. 1995. Isolation of Epstein-Barr-virustransformed lymphocytes producing IgG class monoclonal antibodies using a magnetic cell separator (MACS): preparation of thyroid-stimulat ing IgG antibodies from patients with Graves' disease. Biochem. Biophys. Res. Commun. 207:985-993.

17. Morgenthaler, N.G., et al. 1996. Human immunoglobulin $\mathrm{G}$ autoantibodies to the thyrotropin receptor from Epstein-Barr virus-transformed B lymphocytes: characterization by immunoprecipitation with recombinant antigen and biological activity. J. Clin. Endocrinol. Metab. 81:3155-3161.

18. Marion, S., Ropars, A., Ludgate, M., Braun, J.M. and Charreire, J. 1992. Characterization of monoclonal antibodies to the human thyrotropin receptor. Endocrinology. 130:967-975.

19. Shimojo, N., et al. 1996. Induction of Graves-like disease in mice by immunization with fibroblasts transfected with the thyrotropin receptor and a class II molecule. Proc. Natl. Acad. Sci. USA. 93:11074-11079.

20. Costagliola, S., Rodien, P., Many, M.C., Ludgate, M., and Vassart, G. 1998. Genetic immunization against the human thyrotropin receptor causes thyroiditis and allows production of monoclonal antibodies recognizing the native receptor. J. Immunol. 160:1458-1465.

21. Kaithamana, S., Fan, J., Osuga, Y., Liang, S.G., and Prabhakar, B.S. 1999. Induction of experimental autoimmune Graves' disease in BALB/c mice. J. Immunol. 163:5157-5164.

22. Nagayama, Y., et al. 2002. A novel murine model of Graves' hyperthyroidism with intramuscular injection of adenovirus expressing the thyro- tropin receptor. J. Immunol. 168:2789-2794.

23. Vitti, P., et al. 1993. Detection of thyroid-stimulating antibody using Chinese hamster ovary cells transfected with cloned human thyrotropin receptor. J. Clin. Endocrinol. Metab. 76:499-503.

24. Lengweiler, S., et al. 1999. Preparation of monoclonal antibodies to murine platelet glycoprotein IIb/IIIa (alphaIIbbeta3) and other proteins from hamster-mouse interspecies hybridomas. Biochem. Biophys. Res. Commun. 262:167-173.

25. Davies, T.F., et al. 1998. Development and characterization of monoclonal antibodies specific for the murine thyrotropin receptor. Thyroid. 8:693-701.

26. Morris, J.C., Bergert, E.R., and McCormick, D.J 1993. Structure-function studies of the human thyrotropin receptor. Inhibition of binding of labeled thyrotropin (TSH) by synthetic human TSH receptor peptides. J. Biol. Chem. 268:10900-10905.

27. Tanaka, K., Chazenbalk, G.D., McLachlan, S.M., and Rapoport, B. 1998. Thyrotropin receptor cleavage at site 1 does not involve a specific amino acid motif but instead depends on the presence of the unique, 50 amino acid insertion. J. Biol. Chem. 273:1959-1963.

28. Zeng, F.Y., and Wess, J. 1999. Identification and molecular characterization of $\mathrm{m} 3$ muscarinic dimers. J. Biol. Chem. 274:19487-19497.

29. Oda, Y., et al. 2000. Epitope analysis of the human thyrotropin (TSH) receptor using monoclonal antibodies. Thyroid. 10:1051-1059.

30. Melby, P.C., Chandrasekar, B., Zhao, W., and Coe, J.E. 2001. The hamster as a model of human visceral leishmaniasis: progressive disease and impaired generation of nitric oxide in the face of a prominent Th1-like cytokine response. J. Immunol. 166:1912-1920.

31. Chazenbalk, G.D., McLachlan, S.M., Nagayama, Y., and Rapoport, B. 1996. Is receptor cleavage into two subunits necessary for thyrotropin action? Biochem. Biophys. Res. Commun. 225:479-484. 